Psychopathology 1986;19:1-3

\title{
Contents, Vol. 19, No. 1-2, 1986
}

\section{Contents}

Foreword 4

Classification of Functional Psychoses with Special Reference to Follow-Up Studies

Retterstøl, N 5

'Paranoid Psychoses'. New Aspects of Classification and Prognosis Coming from theVienna

Research GroupBerner, P.; Gabriel, E.; Kieffer, W.; Schanda, H 16

Classification of Chronic Psychoses Including Delusional Disorders and Schizophrenias

Winokur, G 30

The Concept of'Bouffee délirante' with Special Reference to the Scandinavian Conceptof

Reactive PsychosisPichot, $\mathrm{P} 35$

Long-Term Follow-Up of Paranoid Psychoses

Opjordsmoen, $\mathrm{S} \quad 44$

Classification and Prognosis of Schizophrenic Disorders in Light of the Bonn Follow-Up

Studies

Gross, G.; Huber, G 50

Outcome Studies on Schizophrenic Psychoses in Helsinki

Achté, K.; Lönnqvist, J.; Kuusi, K.; Piirtola, O.; Niskanen, P

Prognosis of the Borderline Disorders

Dahl,A.A 68

Genetic Approach to Heterogeneity in Psychoses: Relationship of a Family History ofMania or Depression to Course in Bipolar IllnessWinokur, G.; Crowe, R.; Kadrmas, A 80

S. Status of Twin Research in Functional Psychoses

Kringlen

E 85 